\title{
SOBRE LA INTERกACIONALIZACIÓN DE LA PYME Y SU CONTRIBUCIÓN A LA IMAGEN EXTERIOR DE ESPAก̃A
}

\author{
On the internationalization of SMEs and its \\ contribution to Spain's image abroad
}

\author{
Isidoro Romero \\ Universidad de Sevilla \\ Facultad de CC. Económicas y Empresariales \\ isidoro@us.es \\ María José Rodríguez-Gutiérrez \\ Universidad de Sevilla \\ Facultad de CC. Económicas y Empresariales \\ mjrodri@us.es
}

Este artículo reivindica el papel de las PYME como actores estratégicos en la conformación de una buena imagen exterior de España. En el actual escenario de globalización, en el que la nacionalidad de las grandes corporaciones tiende a diluirse, las PYME podrían llegar a contribuir 1 Autores más establemente a la marca España por su vinculación más permanente y estrecha al territorio. Igualmente, en algunos contextos, como en el caso de Latinoamérica, las PYME podrían coadyuvar a una imagen más amable de España en el exterior.

El trabajo presenta algunos rasgos esenciales del grado y tendencias de internacionalización de la PYME española. Desde esta perspectiva, el artículo analiza los mecanismos y condicionantes que delimitan la contribución potencial que las PYME pueden realizar a la marca España. Asimismo, se señalan algunas ventajas de asociar la imagen exterior de España a las PYME y algunas posibles iniciativas para mejorar la contribución de las PYME internacionalizadas a la marca España. 
This article vindicates the role of SMEs as strategic actors in shaping a good image of Spain abroad. In the current framework of globalization, the nationality of corporations tends to fade. Hence, SMEs could contribute more stably to improving the nation brand of Spain due to its more permanent and close linkage to the territory. Similarly, in some specific contexts, as in the case of Latin America, SMEs could contribute to a more friendly image of Spain abroad.

The paper presents some essential characteristics and trends of the internationalization of Spanish SMEs. From this perspective, the article analyzes the mechanisms and factors which delimit the potential contribution that SMEs can make to the nation brand of Spain. Furthermore, the article points out some advantages of associating the external image of Spain with SMEs and some possible initiatives to enhance the contribution of internationalized SMEs to Spain's national branding project.

\section{Introducción}

La imagen exterior de España se ha configurado tradicionalmente en torno a un reducido grupo de rasgos estereotipados y de vigencia cuestionable en algún caso, referidos a nuestra cultura y estilos de vida. Esta imagen simplificada, que no se ajusta a la complejidad y diversidad de la sociedad española actual, confluye en una idea distorsionada de España como país "bueno para vivir", pero "malo para trabajar" (Lamo de Espinosa, 2013).

A este sesgo característico de nuestra imagen exterior se habrían venido a sumar en los últimos años percepciones negativas vinculadas a la crudeza de la crisis, a sus consecuencias sociales y a una visión de España como problema económico. Estos efectos negativos de la crisis sobre la imagen exterior del país han diluido posiblemente las connotaciones de progreso y modernización que pudieron generarse en el período de expansión anterior, asociadas en parte a la presencia internacional de las grandes empresas españolas.

A este respecto, se suele interpretar que las grandes compañías, con sus marcas reconocidas internacionalmente, actúan como "buques insignia" de la economía nacional, condicionando positivamente la imagen exterior de España ${ }^{1}$. Conforme a esta interpretación, las PYME se beneficiarían en su proceso de internacionalización de la imagen-país fraguada por los grandes grupos empresariales, que generarían con su expansión internacional un efecto arrastre para el resto del tejido empresarial.

Sin embargo, este artículo adopta el punto de vista inverso. En él se reivindica el papel de las PYME como actores estratégicos en la conformación de ese activo intangible que podemos denominar "marca España" 2 . Se defiende aquí que las PYME pueden contribuir de manera notable a la proyección de una buena imagen exterior para la economía española, actuando en algunos contextos, como en el caso de Latinoamérica, como un canal aún más efectivo que las grandes corporaciones.

Para ello se comenzará por presentar, en el segundo apartado, algunos rasgos esenciales del grado y tendencias de internacionalización de la PYME española. Éstas muestran una actividad

1 En cualquier caso, las grandes empresas españolas tienen una presencia global limitada en términos de posicionamiento de sus marcas. Solo la marca Zara se situó entre las 100 con mejor reputación en el mundo en 2013 según el ranking que elabora la consultora Reputation Institute.

2 Siguiendo a González y Casilda (2002) se adopta a lo largo de este artículo la noción "activo-país" o "marca-país" entendida como un "conjunto de fortalezas y debilidades vinculadas al país de origen que incorporan o sustraen el valor suministrado por una marca o servicio al fabricante y/o a sus clientes”. 
exterior menor que la de las grandes empresas, aunque su grado de internacionalización sea similar al de las PYME a escala europea.

No obstante, en las últimas décadas se está incrementando la presencia exterior de las PYME españolas, tanto a través de su acceso a mercados exteriores de exportación, como a través de su presencia directa como inversoras en el extranjero. Este proceso podría estar intensificándose a resultas de la crisis económica, en tanto la caída de la demanda interna estaría empujando a las PYME a abrirse camino en nuevos mercados de exportación.

En este contexto, la influencia que la actividad internacional de la PYME puede tener sobre la imagen exterior de España tenderá a incrementarse en el futuro. Desde esta perspectiva, el apartado tercero de este artículo analiza los mecanismos y condicionantes que delimitan la contribución potencial que las PYME pueden realizar a la marca España. Asimismo, se señalan algunas ventajas de asociar la imagen exterior de España a las PYME y no solo a las grandes empresas, entendidas como "abanderadas" de la economía nacional.

\section{El proceso de internacionalización de la PYME española}

A lo largo de las últimas décadas la empresa española ha abordado un intenso proceso de internacionalización bajo el impulso de la integración europea, la creciente liberalización de los mercados internacionales, la mejora de las redes de transporte y el desarrollo de las tecnologías de la información y las comunicaciones (TIC).

No obstante, el profundo proceso de internacionalización de la economía nacional desde la incorporación de España en 1986 a la entonces Comunidad Económica Europea (CEE) se ha concentrado principalmente en el segmento de las grandes empresas ${ }^{3}$. En la actualidad, un selecto grupo de compañías multinacionales españolas ocupan posiciones relevantes a nivel internacional en sus correspondientes mercados (banca, energía, telecomunicaciones, construcción, moda, entre otros) asumiendo en algunos casos un rol protagonista.

Sin embargo, la española es una economía dual donde las grandes empresas se encuentran a la altura de las grandes corporaciones de las economías más avanzadas en términos de productividad o gasto en I+D, pero las PYME están comparativamente más atrasadas. En estas circunstancias, la PYME española ha quedado rezagada en cuanto a su expansión internacional, y su adaptación al proceso de globalización económica es aún incompleta. Este hecho supone una limitación muy relevante para la economía nacional, dado que las PYME constituyen la base fundamental de cualquier economía y lo son aún con mayor intensidad en el caso de España.

De las 1.464.982 empresas con asalariados existentes en España en 2013, el 99,7\% eran PYME de menos de 200 empleados, según los datos del Directorio Central de Empresas (INE, 2014). Entre ellas, el grupo de microempresas (1-9 asalariados) es el más importante absorbiendo el 90,7\% del total de empresas. Atendiendo al sector de actividad, el 53,1\% de las PYME opera en el sector servicios, siguiéndole en importancia el comercio $(26,3 \%)$ y la construcción $(11,8 \%)$.

3 El concepto de internacionalización empresarial comprende tanto la presencia de la propia empresa (o de sus productos y recursos) en mercados extranjeros, como la utilización por parte de la empresa de recursos exteriores en su proceso productivo y comercial. No obstante, este trabajo adopta una visión limitada de la internacionalización centrándose en la presencia de las empresas españolas o de sus productos y servicios en el extranjero, es decir, de las actividades de exportación y de la inversión directa en el exterior. 
Según un estudio encargado por la Comisión Europea (2013), en España las PYME aportaron en 2012 el 64,8\% del valor añadido total. De acuerdo con el registro de empresas inscritas en la Seguridad Social a diciembre de 2013, las PYME dan empleo en España a 6.891 .461 trabajadores, lo que representa el 57,8\% del empleo total en empresas con al menos un trabajador (Ministerio de Empleo y Seguridad Social, 2014) ${ }^{4}$. Los datos sitúan a España como uno de los países de la Unión Europea en los que más peso tienen las PYME (Ministerio de Industria, Energía y Turismo, 2014).

La importancia de las PYME en el tejido empresarial español recomienda mantener un compromiso firme con la participación de estas empresas en el sector exterior, ya que la actividad internacional de las PYME refuerza su crecimiento, impulsa su nivel de competitividad e innovación y favorece la sostenibilidad de la compañía a largo plazo.

Como puede comprobarse en el gráfico 1, a partir de datos de la Encuesta de Estrategias Empresariales (ESEE), a principios de la década de los noventa del siglo pasado el porcentaje de grandes empresas que exportaban se situaba en el $83 \%$, frente al $31 \%$ para las PYME 5 . Desde entonces, la actividad exportadora de la PYME se ha incrementado de manera notable, de modo que el porcentaje de PYME exportadoras se había duplicado a la altura de 2011. Este proceso de internacionalización podría estar acelerándose en los últimos años en el contexto de la crisis. Ante la caída de la demanda interna, las PYME se están viendo empujadas a salir al exterior como única alternativa a la coyuntura adversa ${ }^{6}$.

\section{Gráfico 1. Evolución del porcentaje de empresas exportadoras por tamaño. 1990-2011.}

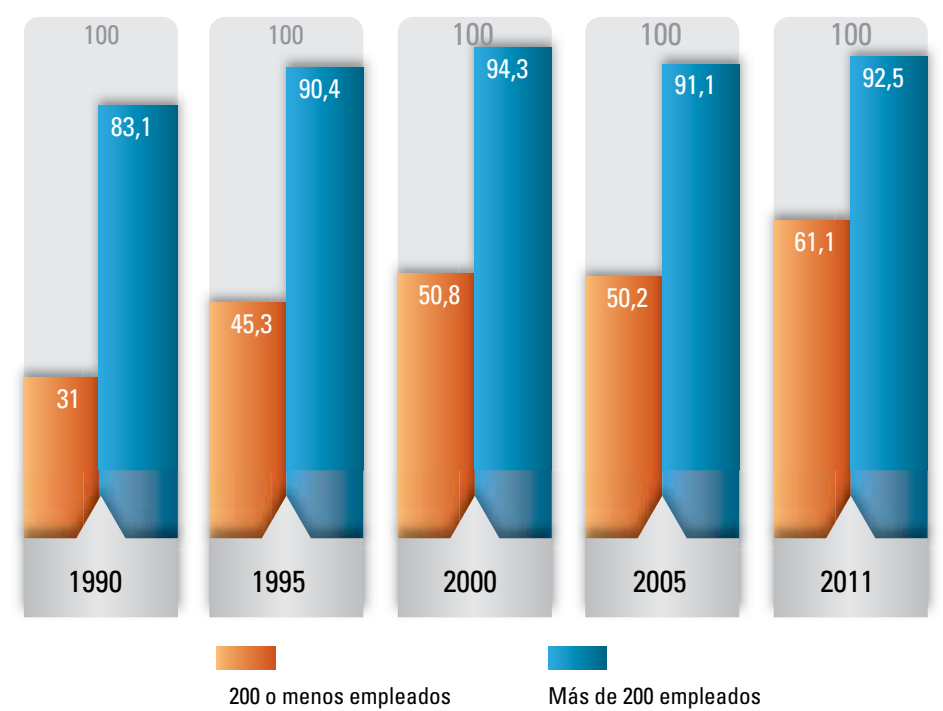

Fuente: Elaboración propia a partir de datos de la Encuesta sobre Estrategias Empresariales-ESEE- (Fundación SEPI, 2014).

Por su parte, la propensión exportadora -porcentaje de las ventas totales que van destinadas al mercado internacional- ha mantenido una tendencia al alza para ambos grupos de empresas

4 Empresas del Régimen General - excluidos los Sistemas Especiales Agrario y de Empleados de Hogar- y del Régimen Especial de la Minería del Carbón. La clasificación por tamaño del registro de empresas de la Seguridad Social considera PYME a las empresas entre 1 y 249 asalariados.

5 La ESEE proporciona información sobre las características y estrategias empresariales de una muestra representativa de empresas de más de diez trabajadores pertenecientes a las industrias manufactureras.

6 La base exportadora de España creció más de un 10\% en 2013 y el número de empresas exportadoras supera las 150.000 (Expansión, 2014). 
desde los años noventa, aunque la evolución de las ventas exteriores de las PYME se ve más afectada por el ciclo de la economía española (véase gráfico 2). Entre las grandes empresas, las exportaciones crecieron de forma continua y con mayor intensidad durante todo el periodo, mientras que en el caso de las PYME se observa cierto estancamiento hasta el estallido de la actual crisis económica, cuando se aceleró el crecimiento de las ventas exteriores provocando un aumento de su propensión exportadora.

Como consecuencia de la importancia del sector de la PYME en el conjunto de la economía española y su menor internacionalización, la base exportadora de la economía nacional resulta limitada. De este modo, según los datos del Banco de España, solo un 12\% de las empresas españolas exportó bienes y un 9\% exportó servicios no turísticos durante el período 20012011. Asimismo, la dualidad de la estructura empresarial española determina un alto grado de concentración de las exportaciones; de modo que el 1\% de las empresas con mayor volumen exportador acapara el 67\% del total de las exportaciones. La cifra asciende al $93 \%$ cuando se considera el 10\% de las mayores empresas exportadoras (Correa-López y Doménech, 2012).

Gráfico 2. Evolución de la propensión exportadora según tamaño. 1990-2011.

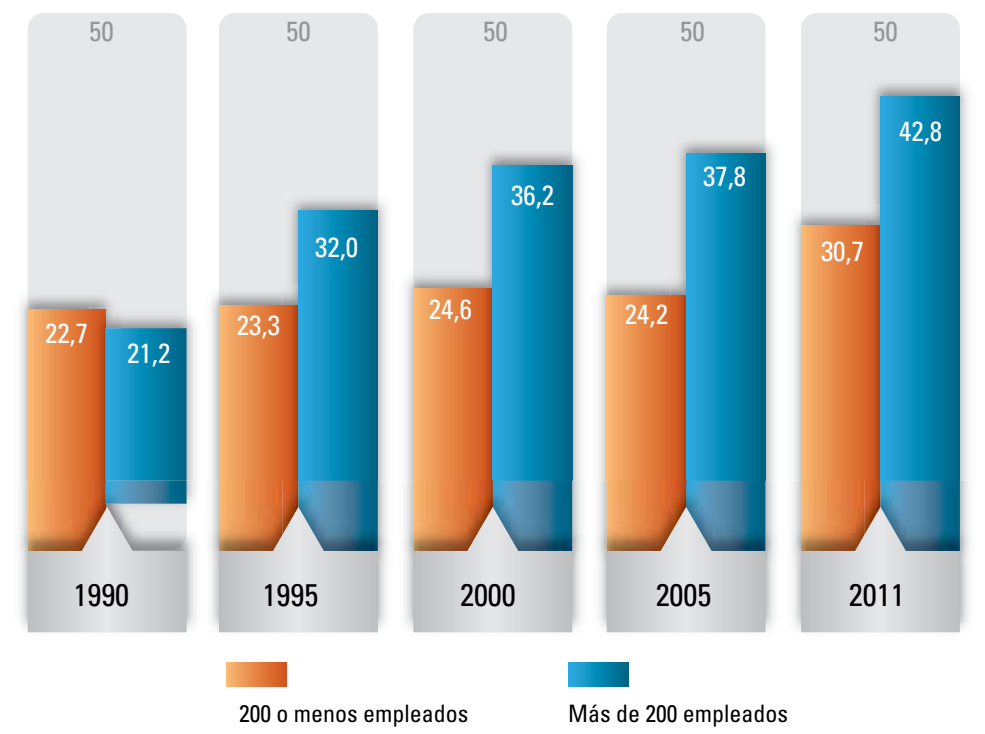

Fuente: Elaboración propia a partir de datos de la ESEE (Fundación SEPI, 2014).

La menor actividad exportadora de las PYME españolas es el resultado de un conjunto de factores entre los que se pueden señalar su baja calidad emprendedora (Fernández-Serrano y Romero, 2013), unas condiciones del entorno que dificultan el desarrollo de las PYME (Banco Mundial, 2013) o los problemas de competitividad derivados de su reducido tamaño medio, su baja productividad y eficiencia, o su bajo nivel tecnológico, entre otros aspectos (Camisón y de Lucio, 2010).

Junto a la exportación, algunas empresas españolas han optado por estrategias de internacionalización más avanzadas, implantándose en los mercados exteriores. Desde mediados de la década de los noventa se asiste a un incremento sustancial de los flujos de inversión directa española en el exterior, siendo cada vez más las empresas españolas que han consolidado su presencia internacional. Una parte sustancial de esa inversión es efectuada por las empresas de mayor tamaño. Según la Encuesta sobre Estrategias Empresariales (ESEE), en 2011 el porcentaje de empresas de más de 200 trabajadores con participación en el capital social de otras empresas 
localizadas en el extranjero fue del $37,1 \%$. Este porcentaje es sustancialmente inferior en el caso de las empresas de menor tamaño, donde alcanzó el 7,1\% (gráfico 3).

\section{Gráfico 3. Evolución del porcentaje de empresas con participación en el capital social de otras} empresas localizadas en el extranjero por tamaño 2000-2011
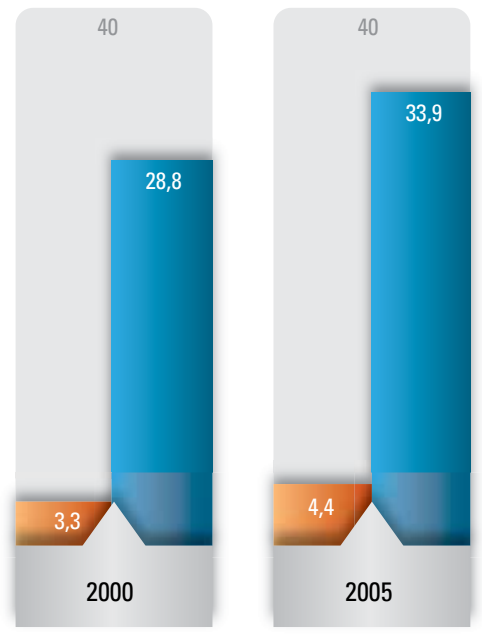

200 o menos empleados
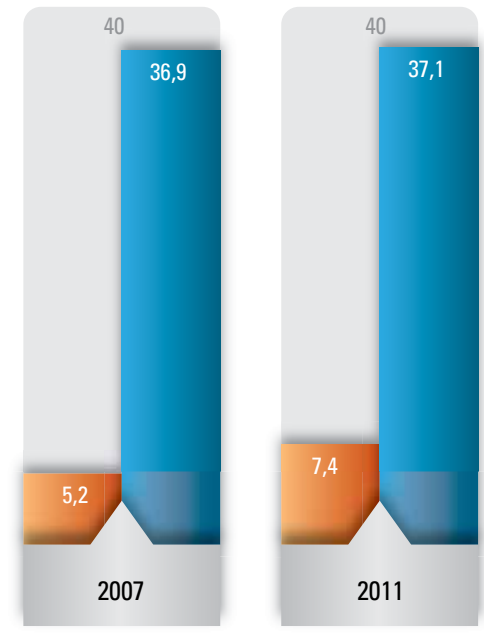

Más de 200 empleados

Fuente: Elaboración propia a partir de datos de la ESEE (Fundación SEPI, 2014).

En relación al área geográfica de destino de las inversiones directas, las empresas participadas por PYME españolas se encuentran por lo general en la Unión Europea, seguida de Latinoamérica (gráfico 4). Las empresas localizadas en el extranjero y participadas por empresas españolas de 200 o menos trabajadores realizan principalmente actividades de comercialización o distribución (50\%), mientras que las empresas de más de 200 trabajadores participan mayoritariamente en empresas que elaboran productos similares a los de la matriz en España $(61,2 \%)$ (Fundación SEPI, 2013)

Gráfico 4. Empresas con participación en otras empresas según área geográfica y tamaño. 2011 (*)

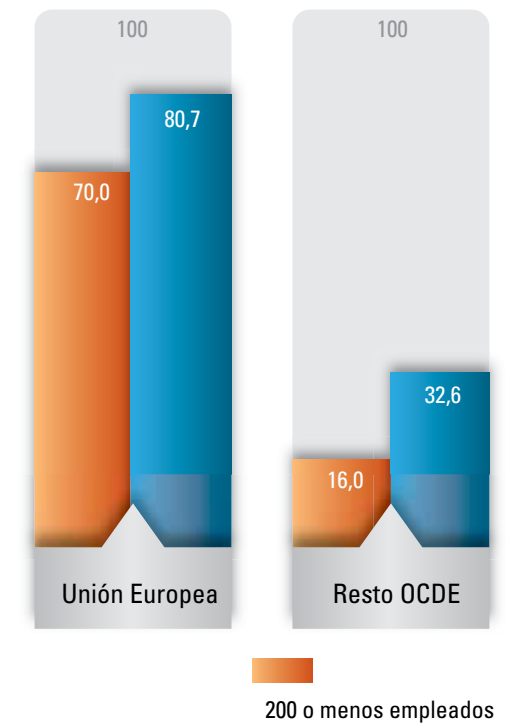

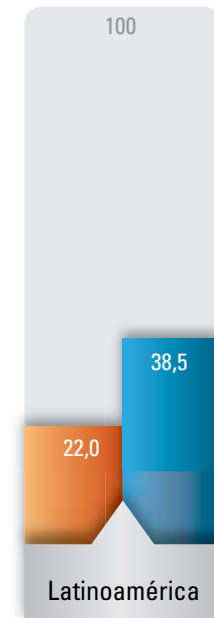

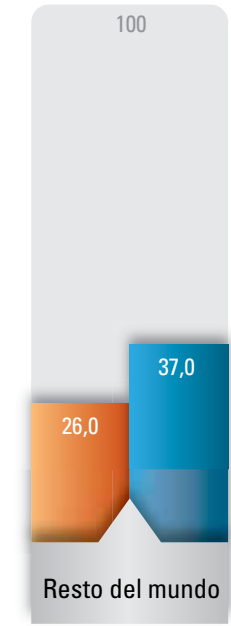

Más de 200 empleados

Fuente: Elaboración propia a partir de datos de la ESEE (Fundación SEPI, 2014).

(*) Porcentajes sobre el total de empresas con participación en otras empresas localizadas en el extranjero. 
Desde una perspectiva internacional, según un estudio encargado por la Comisión Europea sobre la internacionalización de las PYME europeas (EIM, 2010), España presenta un porcentaje de PYME exportadoras ligeramente inferior a la media de la UE-27, coincidiendo en ello con otras grandes economías de la UE como Alemania, Reino Unido o Francia (gráfico 5).

Gráfico 5. Porcentaje de PYME exportadoras. 2006-2008.

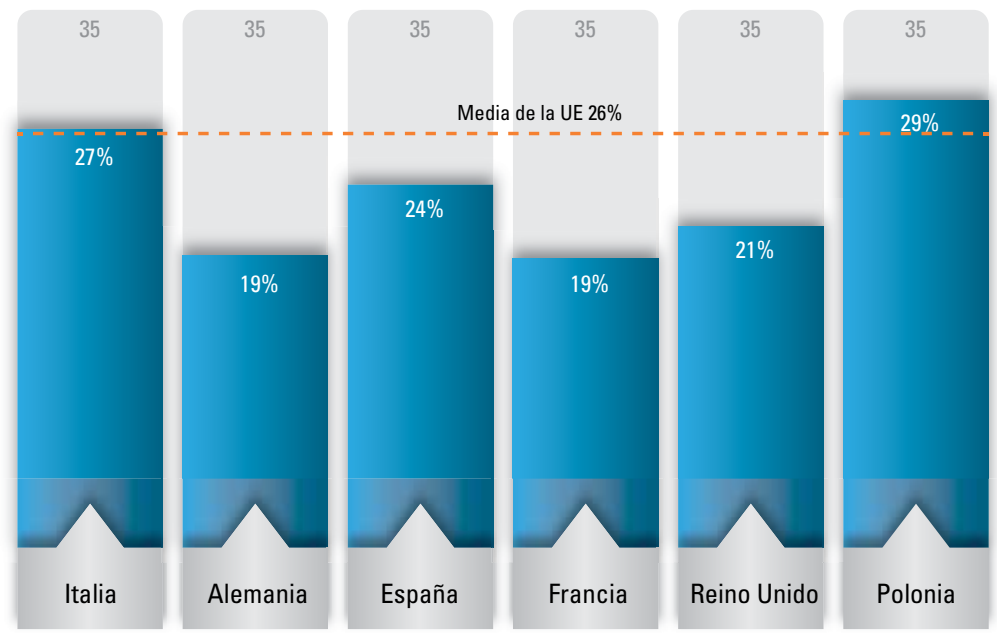

Fuente: Elaboración propia con datos de EIM (2010).

Asimismo, el número de PYME españolas que participan en inversiones directas en el exterior $(2,1 \%)$ es similar a la media de la Unión Europea (2,3\%) (EIM, 2010). No obstante, si se consideran otros aspectos relacionados con las inversiones directas, como son las relaciones de cooperación técnica o la subcontratación de empresas extranjeras, el nivel de internacionalización de las PYME españolas resulta inferior al de la mayoría de los países de la Unión Europea. Considerando globalmente todas las dimensiones de la internacionalización empresarial, las PYME españolas, en términos generales, muestran un nivel de internacionalización similar al de sus homólogas en la Unión Europea (EIM, 2010).

\section{PYME e imagen de España en el exterior}

La imagen de los países se conforma en torno a tres factores principales: aspectos instrumentales (relacionados con la eficiencia, la seriedad y el rigor, o los negocios), aspectos expresivos (relacionados con el ocio, la diversión y el entretenimiento) y un tercer factor, menos definido, vinculado a la idea de calidad (Lamo de Espinosa, 2013).

Pues bien, la imagen de España, en comparación internacional, figura en las primeras posiciones en las dimensiones expresivas, pero en las últimas en las dimensiones instrumentales. Según un estudio de Reputation Institute, los ciudadanos del G8 recomendarían vivir en España 10 puntos más que lo harían respecto a otro país del G8. Sin embargo, recomendarían invertir en España 10 puntos menos y recomendarían comprar productos españoles 5 puntos menos (Lamo de Espinosa, 2013). España tiene, por lo tanto, un amplio margen de mejora en cuanto a la dimensión económica-instrumental de su imagen exterior?

7 Este análisis, generalmente compartido en España, es también asumido por observadores internacionales. En palabras del prestigioso seminario británico The Economist, en un artículo reciente bajo el titulo "Made in Spain. A pressing issue", "[...] the country clearly has some way to go in raising the prestige of the Made in Spain label". 
En este sentido, la construcción de la marca España como un marchamo de eficiencia económica sería muy importante por sus repercusiones sobre las empresas nacionales favoreciendo la exportación de bienes y servicios y mejorando el atractivo de nuestro país como destino de la inversión extranjera.

Las PYME serían las mayores beneficiarias de una mejor imagen-país. Las grandes empresas pueden desarrollar marcas propias bien posicionadas y no verse tan influenciadas por el efecto país de origen. Sin embargo, las PYME carecen frecuentemente de marcas reconocibles y de recursos para introducirlas ${ }^{8}$, de modo que la marca-país puede resultar un condicionante fundamental.

No obstante, la relación de influencia entre la marca-país y la internacionalización de las empresas españolas se manifiesta también en el sentido inverso: una mayor presencia internacional de las empresas españolas, consolidando una imagen de marca positiva en el exterior, mejoraría a su vez los aspectos instrumentales de la marca España como activo-país.

En este sentido, como señala Otero (2013), la imagen-país y la imagen de marca de las empresas nacionales en el exterior son variables que se retroalimentan: una mayor presencia de marcas nacionales en el exterior genera de forma directa una mejor imagen-país y, al mismo tiempo, una mejor imagen-país constituye un atributo diferenciador que favorece la internacionalización de las marcas nacionales. Se produce así un efecto sinérgico o de "fertilización cruzada” (González y Casilda, 2002).

Este artículo, en función de sus objetivos, se ocupa particularmente de uno de los sentidos de esta interacción: la contribución de las empresas internacionalizadas, y concretamente de las PYME, a la construcción de la imagen exterior de España.

A resultas del proceso de globalización, las empresas originarias de un país y sus productos circulan internacionalmente y están presentes en muchos otros países. De este modo, los consumidores compran en su día a día productos procedentes de naciones donde probablemente nunca hayan estado, así como bienes y servicios producidos en su propio país por empresas procedentes de otros países. A partir de estas experiencias particulares de consumo, los individuos conforman un conjunto de significados que asocian al país de origen del producto/empresa. Como apunta Otero (2013), "en este universo, las empresas y marcas son de sus países y los países son fabricantes de marcas y productos”. Este fenómeno de identificación determina que las empresas y marcas de un país actúen en cierta medida como "embajadores" nacionales.

Conviene señalar que el proceso de internacionalización de las empresas está dando lugar, en el caso de las grandes compañías, a grupos transnacionales en los que resulta cada vez más discutible asociar la empresa a una nacionalidad. Este proceso afecta también a las grandes corporaciones españolas que, en algunos casos, muestran una elevada penetración del capital extranjero en su accionariado y obtienen más beneficios, tienen más empleados o invierten más en el extranjero que en la propia España. En estas circunstancias, cabe preguntarse hasta qué punto siguen siendo "españolas" algunas grandes empresas "españolas" 9.

8 En un estudio sobre la internacionalización de la PYME española realizado por la Fundación EOI (2012) se muestra cómo, incluso entre las propias PYME con actividad exterior, un mayor tamaño está asociado con una mayor actividad de publicidad en mercados externos. En las empresas de menos de 10 trabajadores solo una de cada cuatro había realizado algún tipo de publicidad exterior, mientras que en las PYME entre 26 y 50 empleados esta proporción se elevaba prácticamente a la mitad.

9 A título ilustrativo, Ignacio Sánchez Galán, Presidente de Iberdrola, afirmó en una comparecencia pública en Londres en febrero de 2014: "Somos más británicos, americanos y mexicanos que españoles", en alusión al peso de cada negocio en las cuentas de la empresa (Expansión, 2014).

Hasta qué punto
siguen siendo
"españolas"
algunas grandes
empresas
"españolas"

Hasta qué punto siguen siendo "españolas" empresas 
A pesar de ello no cabe duda de que, en la mayor parte de los casos, el país de origen asociado a una empresa o sus marcas sigue agregando connotaciones a la imagen de marca de los productos y que, recíprocamente, la imagen de marca de las grandes empresas influencia significativamente la imagen-país. No obstante, la capacidad de las grandes empresas de contribuir a la marca España podría estar diluyéndose en algunos casos. Por el contrario, resulta razonable pensar que la identificación de la PYME con el territorio es mucho más intensa y permanente que en el caso de la gran empresa. Esta circunstancia eleva el potencial de las PYME internacionalizadas como cauce para la creación de la marca-país.

A este respecto, algunas grandes corporaciones, en función de su estrategia global de marketing, pueden llegar a preferir que no se las asocie con una nacionalidad. González y Casilda (2002) ilustran este fenómeno desde una perspectiva internacional con el caso de Danone. Esta compañía busca ser percibida en su proceso de internacionalización como una marca multilocal y no como una marca francesa o internacional. Como resultado, si preguntáramos en España sobre la nacionalidad de Danone, muchos de los consumidores probablemente responderían que es una marca española. Este fenómeno se aprecia también en el caso de las empresas españolas, de tal modo que muchas firmas procuran disociar su imagen de marca al "Made in Spain” optando por insinuar un origen distinto, por ejemplo, utilizando nombres italianos (Peralba, 2009). Se trata con ello de eludir algunas connotaciones negativas de la imagen-país de España y/o vincular su producto a percepciones positivas asociadas a otras nacionalidades, para conseguir así alguna ventaja competitiva.

Ciertamente, hay que tener en cuenta que la imagen del país de origen puede tener efectos negativos sobre la percepción y el comportamiento del consumidor respecto a las marcas o empresas de esa nacionalidad. En algún caso extremo puede existir incluso un fenómeno de "animosidad" frente al país de origen, entendida ésta como una antipatía derivada de conflictos históricos o actuales, de carácter militar, político o económico, con efectos directos sobre las decisiones de compra de los consumidores respecto a las marcas nacionales. La animosidad puede estar presente en forma de una rivalidad saludable, de un enfrentamiento enconado, o generarse como reacción a lo que se percibe como prácticas comerciales ilegítimas desarrolladas por determinados países (González y Casilda, 2002).

En el caso de España cabría apreciar una cierta animosidad en algunos colectivos sociales en Latinoamérica, región que, paradójicamente, ha sido uno de los destinos más importantes de la inversión directa de las grandes empresas españolas en las últimas décadas. Así pues, en un estudio internacional de marcas - Brand Asset Valuator- realizado por Young \& Rubicam se apreciaba como la valoración de España en los países europeos es mejor que la obtenida en los países latinoamericanos, respecto a los que se observó un cierto alejamiento emocional. España es vista frecuentemente en Latinoamérica como un país progresista, pero arrogante e incluso distante (González y Casilda, 2002).

Esta percepción, evidentemente derivada de la historia común de colonización de Latinoamérica por España, podría estar avivándose en las últimas décadas ante la implantación de las grandes compañías españolas en la región. Algunos grupos sociales parecen contemplar a las grandes corporaciones españolas como "nuevos conquistadores", atribuyéndoles un afán explotador y señalándolos como el origen de ciertos problemas económicos nacionales. Esta visión puede ser instrumentalizada fácilmente por gobiernos populistas propiciando conflictos con las grandes empresas españolas como estrategia para generar una imagen positiva de fortaleza y firmeza y así mejorar su valoración pública. 
En este contexto, pueden incardinarse diversos enfrentamientos producidos en la última década entre gobiernos de países latinoamericanos, como Venezuela, Bolivia o Argentina, y las grandes empresas españolas con presencia en la región, dando lugar a procesos de expropiación, nacionalización, retirada de licencias o conclusión anticipada de contratos de suministro ${ }^{10}$.

En situaciones de alta animosidad hacia el país de origen en el mercado objetivo, las empresas deben diseñar su estrategia de marketing con el objetivo de responder a las condiciones socioculturales adversas. Actuaciones en el campo de la comunicación y de las relaciones públicas o acuerdos para la fabricación local desarrollando "marcas híbridas" se encuentran entre las posibles actuaciones. Decisiones estratégicas como la que adoptó Repsol al unir su nombre de marca a la de la petrolera argentina YPF tras la adquisición de esta compañía en 1999, dando lugar a la marca Repsol-YPF, cabe valorarlas en este contexto (González y Casilda, 2002).

Asimismo, las grandes empresas no siempre son origen de buenas noticias ni contribuyen continuamente a una imagen positiva del país con su actividad y decisiones. Por el contrario, las actuaciones de las grandes corporaciones pueden producir impactos negativos sobre la imagen exterior y generar sentimientos de rechazo. La experiencia de las grandes empresas españolas en Latinoamérica permite también ilustrar esta circunstancia con casos recientes como el conflicto entre la Autoridad del Canal de Panamá y el consorcio liderado por la constructora española Sacyr por el sobrecoste de las obras de ampliación del Canal. Este tipo de enfrentamientos deteriora indudablemente la marca España, con los consecuentes impactos negativos sobre el resto de empresas españolas en su actividad internacional.

A este respecto, la internacionalización de las PYME difícilmente puede suscitar impactos negativos de esta naturaleza y dimensión, sino que, por el contrario, representan una cara más “amable" de España en Latinoamérica. De este modo, una presencia más intensa de las PYME españolas en esta región permitiría hacer compatible y reforzar la imagen positiva de eficiencia y modernidad que se asocia en Latinoamérica a la marca España con un perfil más bajo y menos "agresivo" que es consubstancial a las PYME dada su menor dimensión. Las PYME difícilmente pueden ser percibidas como agentes colonizadores o explotadores a los que achacar determinados problemas locales.

La actividad de las PYME en el exterior podría contribuir también positivamente a la imagenpaís de España y generar percepciones positivas sobre la economía nacional, facilitando la atracción de inversiones externas. La creciente presencia internacional de las PYME españolas podría coadyuvar a la mejora de la imagen del país como un entorno adecuado para hacer negocios, donde resulta fácil encontrar proveedores especializados que contribuyan al éxito de los proyectos de inversión.

Disponer de un tejido eficiente de PYME es un factor competitivo de creciente importancia ante la transformación de los modos de producción asociada a la globalización. En este escenario los procesos productivos se están fragmentando funcional y espacialmente, de modo que las distintas etapas de la cadena de valor de un producto o servicio son frecuentemente

10 El gobierno venezolano amenazó con la nacionalización del Banco de Venezuela, filial del Banco Santander, en 2008. El conflicto terminó con la venta de dicho banco al estado venezolano en 2009. Bolivia nacionalizó activos de Repsol-YPF en 2008, de Iberdrola en 2012, de Red Eléctrica Española en 2012 y de Abertis y Aena en 2013. El gobierno argentino expropió Aerolíneas Argentinas y Austral a Marsans en 2008, nacionalizó un fondo de pensiones del BBVA en 2008 y expropió YPF a Repsol en 2012. Asimismo, retiró concesiones en el sector del agua a otras empresas de capital español.

Las PYME

representan una cara más "amable" de España en Latinoamérica 
ejecutadas por diversas empresas, en muchos casos PYME, localizadas en distintos puntos de la geografía mundial. Se está dando lugar así a la formación y desarrollo de cadenas de valor globales lideradas por grandes corporaciones estrechamente ligadas a PYME que actúan como sus proveedores o distribuidores especializados (Romero, 2009).

En este sentido, la progresiva internacionalización de las PYME españolas debería acompañarse sin lugar a dudas de políticas de reforma internas que garanticen una mejora de las condiciones regulatorias, administrativas y económicas que conforman el entorno empresarial (Romero, 2006). Hoy por hoy, España muestra al mundo una imagen muy poco favorable a este respecto, como evidencia anualmente el informe Doing Business elaborado por el Banco Mundial (2013), que sitúa a España en la posición 52 por facilidad para hacer negocios entre un total de 189 países analizados.

En la medida en que mejoraran las condiciones del entorno empresarial y se transmitiera una imagen de España como un país business friendly aumentaría también la capacidad de la economía nacional para atraer emprendedores de otras nacionalidades que eligieran nuestro país para poner en marcha nuevos proyectos. En esta dirección, la Ley 14/2013 de 27 de septiembre de apoyo a los emprendedores y su internacionalización (Ley 14/2013) ha introducido la autorización de residencia para inversores y emprendedores que deseen desarrollar un proyecto de interés general en España. No obstante, para poder crear una imagen de España como país abierto al talento y la capacidad emprendedora extranjera queda un gran trabajo por desarrollar, mejorando las condiciones de nuestro entorno empresarial, que en la actualidad, como acabamos de señalar, se encuentra lejos de las mejores referencias internacionales.

Los inmigrantes españoles que emprendieron alguna actividad económica en el extranjero pueden ser también un activo que contribuya a la mejora de la imagen exterior de España, así como un cauce de estrechamiento de las relaciones económicas y socio-culturales con sus países de residencia. La importancia de este colectivo puede aumentar en el futuro como consecuencia de la ola actual de emigración española y el proceso de internacionalización de la PYME impulsada por la crisis económica en nuestro país. Asimismo, la integración de esos empresarios en los países de acogida puede ser un factor mitigador de los posibles fenómenos de animosidad, allí donde pudieran manifestarse, y añadir percepciones de cercanía emocional que fortalezcan la imagen-país de España.

\section{Conclusión}

La imagen exterior de un país es un activo intangible que favorece la actividad económica, en particular, la internacionalización empresarial, la atracción de inversiones o el desarrollo turístico. Los países que han conformado una imagen exterior asociada a percepciones positivas disfrutan de ventajas competitivas que añaden valor a sus productos o servicios y elevan el atractivo de su territorio como destino de inversión. Por el contrario, una imagen-país con connotaciones negativas actúa como un obstáculo para las empresas nacionales en su proyección exterior, reduciendo su capacidad competitiva.

La imagen exterior de España en las últimas décadas ha estado marcada, por lo general, por factores no económicos, como su proceso de democratización, los grandes referentes de nuestra cultura y deporte o el estilo de vida. Por el contrario, la imagen exterior del país no se cimenta en percepciones positivas sobre la calidad de sus productos y servicios o la eficiencia de su

La imagen exterior de un país es un activo intangible que favorece la actividad económica 
economía, lo que limita la proyección internacional de las empresas españolas y el atractivo de España como destino de talento e inversión empresarial.

He aquí un campo de actuación de gran valor estratégico para el futuro de la economía nacional en el contexto de la globalización: moldear la marca España incorporando connotaciones instrumentales de eficiencia, calidad e innovación sin menoscabar las fortalezas de una potente imagen exterior asociada a rasgos socio-culturales e idiosincráticos.

A este respecto, hay que tener en cuenta que las empresas no son meras receptoras de la imagen exterior del país, sino que contribuyen a conformarla. Existe un mecanismo bidireccional en función del cual la marca-país aporta valor a las marcas comerciales nacionales y a su vez las marcas nacionales reputadas contribuyen a una mejor percepción de la marca-país.

De este modo, en las últimas décadas la presencia internacional de las grandes corporaciones españolas ha podido contribuir positivamente a una mejor imagen exterior de la economía nacional. Sin embargo, especialmente en Latinoamérica, segundo mayor destino de la inversión española en el exterior, las grandes empresas españolas se enfrentan a una cierta animosidad derivada de factores históricos. En algunos países latinoamericanos la presencia de estas grandes corporaciones en sectores básicos para los consumidores y el sistema productivo (energético, telecomunicaciones, suministro de agua, infraestructuras, banca, etc.) ha podido consolidar en las últimas décadas ciertas percepciones negativas asociadas a la imagen de España.

Marca España debería prestar más atención a las PYME con presencia internacional

Por su parte, las PYME españolas muestran un nivel de internacionalización por debajo del de las grandes empresas. Sin embargo, están incrementando significativamente su presencia en el exterior en un proceso que cabe esperar continúe y se fortalezca en los próximos años. Las PYME están llamadas pues a desempeñar un papel crecientemente relevante como "embajadoras” de la marca España. En el contexto de globalización, en el que la nacionalidad de las grandes corporaciones tiende a diluirse, las PYME podrían llegar a contribuir más establemente a la marca España que las propias grandes empresas, por su vinculación más permanente y estrecha al territorio.

Cabe concebir un escenario en el que algunas grandes empresas españolas busquen proyectarse como empresas globales, que prefieran no identificarse con la marca-país. Ciertas grandes empresas, en su intento de consolidar marcas globales mundialmente reconocidas y percibidas con atributos positivos, podrían tratar de escapar de posibles percepciones instrumentales negativas asociadas a la imagen-país de España como una economía frágil y periférica en la UE. En este contexto, la imagen exterior de España dejaría de gravitar tan estrechamente sobre las grandes corporaciones de origen nacional y quedaría vinculada en mayor medida a la imagen exterior de las PYME.

En función de este escenario podrían ser las PYME en el futuro las mayores responsables de mejorar la percepción internacional de la marca España, asociándola a connotaciones de eficiencia económica. Asimismo, serían también las PYME las que más se beneficiarían de una imagen-país positiva, actuando ésta como una marca corporativa paraguas que cobije a las PYME sin marcas reconocidas en su proceso de internacionalización. Desde esta perspectiva, por su propia condición, las PYME se encuentran más estrechamente vinculadas a la marca España y dependen más de ella.

En este sentido, consideramos que la política marca España debería prestar más atención al impacto de las PYME españolas con presencia internacional. A este respecto, convendría desa- 
rrollar actuaciones en el exterior que asocien la imagen-país de la economía nacional al éxito de PYME españolas internacionalizadas que representen modelos de excelencia.

Asimismo, cabría diseñar acciones orientadas a concienciar a las PYME con presencia exterior sobre su papel como "embajadoras" de nuestra economía. Conviene hacer sentir a las PYME su responsabilidad como constructores de la marca España a través de los atributos de sus productos y servicios, de la ética de sus negocios o de su capacidad de integración en las economías de destino mostrando una cara moderna y amable de España. Con ello se conseguiría reforzar las sinergias asociadas al binomio conformado por la marca-país y las marcas corporativas y potenciar así la necesaria internacionalización de las PYME españolas.

\section{Bibliografía}

Banco Mundial (2013). Doing Business 2014 Entendiendo las regulaciones para las pequeñas y medianas empresas. Washington, DC: Banco Mundial.

Camisón Zornoza, C., \& de Lucio Fernández, J. J. (2010). La competitividad de las PYMES españolas ante el reto de la globalización. Economía industrial, (375), 19-40.

Comisión Europea (2013). A recovery on the horizon? Annual report on European SMEs 2012/2013. Bruselas: Comisión Europea.

http://ec.europa.eu/enterprise/policies/sme/facts-figures-analysis/performance-review/ index_en.htm

Correa-López, M., \& Doménech, R. (2012). La Internacionalización de las Empresas Españolas. Documentos de Trabajo BBVA Research, Número 12/29.

EIM (2010). Internationalisation of European SMEs. Bruselas: Comisión Europea.

http://ec.europa.eu/enterprise/policies/sme/market-access/files/internationalisation_of_ european_smes_final_en.pdf

Expansión (2014). Comercio calcula que ya hay más de 150.000 empresas exportadoras. Expansión (25 de Marzo).

http://www.expansion.com/2014/03/25/economia/1395746903.html

Expansión (2014). Galán (Iberdrola) dice que el negocio de generación en España "pierde dinero". Expansión (19 de Febrero).

http://www.expansion.com/agencia/efe/2014/02/19/19240473.html

Fernández-Serrano, J., \& Romero, I. (2013). Entrepreneurial quality and regional development: Characterising SME sectors in low income áreas. Papers in Regional Science, 92(3), 495-513.

Fundación EOI (2012). Tendencias hacia la internacionalización de las pymes españolas 2011. Madrid: Fundación Escuela de Organización Industrial.

Fundación SEPI (2014). Encuesta sobre estrategias empresariales. Madrid: Ministerio de Hacienda y Administraciones Públicas.

http://www.fundacionsepi.es/esee/sp/spresentacion.asp

Fundación SEPI (2013). Las empresas industriales en 2011. Madrid: Ministerio de Hacienda y Administraciones Públicas. 
http://www.fundacionsepi.es/ESEE/sp/INFORME_ESEE_2011.pdf

González Silvestre E., \& Casilda Béjar, R. (2002). La marca país como ventaja competitiva. El valor de la marca España. Información Comercial Española, (799), 101-113.

INE (2014). Directorio Central de Empresas. Madrid: Instituto Nacional de Estadística. http://www.ine.es/jaxi/menu.do?type $=$ pcaxis\&path $=\% 2 \mathrm{Ft} 37 \% 2 \mathrm{Fp} 201 \&$ file $=$ inebase $\& \mathrm{~L}=0$

Lamo de Espinosa, E. (2013). La marca España. Bueno para vivir, malo para trabajar. Economistas, (134), 27-36.

Ministerio de Empleo y Seguridad Social (2014). Registro de empresas inscritas en la Seguridad Social. Madrid: Subdirección General de Estadística Sociales y Laborales. http://www.empleo.gob.es/series/

Ministerio de Industria, Energía y Turismo (2014). Informe sobre la PYME 2012. Madrid: Dirección General de Industria y de la Pequeña y Mediana Empresa. http://www.ipyme.org/Publicaciones/Informe-PYME2012.pdf

Otero, M. (2013). La imagen país, crucial para la competitividad de las empresas. Economía Industrial, (387), 131-134.

Peralba Fortuny, R. (2009). La Imagen Exterior de España y la Competitividad. El posicionamiento estratégico de la marca España. Madrid: Círculo de Empresarios.

Romero, I. (2006). Las PYME en la economía global. Hacia una estrategia de fomento empresarial. Problemas del desarrollo. Revista Latinoamericana de Economía, 37(146), 31-50.

Romero, I. (2009). Pymes y Cadenas de Valor Globales. Implicaciones para la política industrial en las economías en desarrollo. Análisis Económico. XXIV (57), 199-216.

The Economist (2014, 19 de abril). Made in Spain. A pressing issue. The Economist.

http://www.economist.com/news/business/21600996-government-frets-about-foreignhands-nations-olive-presses-pressing-issue 